\title{
An extended hesitant fuzzy set using SWARA-MULTIMOORA approach to adapt online education for the control of the pandemic spread of COVID-19 in higher education institutions
}

\author{
Mahyar Kamali Saraji ${ }^{1,6}$. Abbas Mardani ${ }^{2}$ Mario Köppen ${ }^{3}$. Arunodaya Raj Mishra ${ }^{4}$. \\ Pratibha Rani ${ }^{5}$
}

Accepted: 28 May 2021 / Published online: 3 June 2021

(c) The Author(s), under exclusive licence to Springer Nature B.V. 2021

\begin{abstract}
The world has been challenged since late 2019 by COVID-19. Higher education institutions have faced various challenges in adapting online education to control the pandemic spread of COVID-19. The present study aims to conduct a survey study through the interview and scrutinizing the literature to find the key challenges. Subsequently, an integrated MCDM framework, including Stepwise Weight Assessment Ratio Analysis (SWARA) and Multiple Objective Optimization based on Ratio Analysis plus Full Multiplicative Form (MULTIMOORA), is developed. The SWARA procedure is applied to the analysis and assesses the challenges to adapt the online education during the COVID-19 outbreak, and the MULTIMOORA approach is utilized to rank the higher education institutions on hesitant fuzzy sets. Further, an illustrative case study is considered to express the proposed idea's feasibility and efficacy in real-world decision-making. Finally, the obtained result is compared with other existing approaches, confirming the proposed framework's strength and steadiness. The identified challenges were systemic, pedagogical, and psychological challenges, while the analysis results found that the pedagogical challenges, including the lack of experience and student engagement, were the main essential challenges to adapting online education in higher education institutions during the COVID-19 outbreak.
\end{abstract}

Keywords Adapted online education - Higher education institutions · Hesitant fuzzy sets · Multi-criteria decision making $(\mathrm{MCDM}) \cdot$ Fuzzy sets

\section{Introduction}

The world has been challenged since late 2019 by the COVID-19 detected in Wuhan, China, for the first time. Although the number of people infected by coronavirus was rapid growth since then, the world leaders initially disregard COVID-19. As a result, it became a pandemic having considerable adverse effects on economics, education, people's life, etc.

Abbas Mardani

abbas.mardani.edu@gmail.com

Extended author information available on the last page of the article 
(Gössling et al. 2020). Also, there are two main strategies for fighting with COVID-19, including lockdown and social distancing, which are implementing by the world's authorities, while each of the mentioned strategies may affect many aspects of people's lives, especially their daily interactions and education system (Lau et al. 2020). On top of that, the education system is on the front line since it is believed the knowledge is the main factor to know the way of beating COVID-19, while knowledge transferring happens based on a new form of education named online education (Grammegna 2020). The shortcomings of the world education system as to online education have been revealed so that most universities in the world have to tackle various challenges to complete their unfinished semester (Naciri and Kharbach 2020). For instance, Iranian universities and schools closed on March 5, while not only the number of appropriate platforms for online education was not enough to deal with the situation, but also there was a high number of technical challenges which both the government and students have been encountered (Bizaer 2020). On top of that, many teachers and students do not have the technological know-how to face problematic situations to adapt to online education. Also, they have to use online platforms as only means of teaching, while these platforms were utilized as supplementary teaching material.

Besides, the development of online education has internationally improved in light of communication and information technologies. Recently, higher education providers offer online courses both on and off-campus in response to this trend in the world. Due to online education benefits, including adjustable speed of study, more affordable tuition fees, and greater cultural diversity, many students tend to enroll in online classes (Damary et al. 2017). However, some growing concerns have remained, including a lack of appropriate materials and a lack of suitable interaction tasks, and so on. As a result, it negatively affects students, especially the international students, since they may face various challenges, including those challenges related to existing differences between social communication in online learning environments (Rovai and Barnum 2007). In this vein, institutions should handle different challenges to use online platforms to resume their incomplete programs. Thus, a comprehensive framework of challenges is needed in which the importance of the challenges is evaluated using a novel MCDM method to help institutions deal with the current problematic situation.

The present study's main contributions are, first, developing a comprehensive framework in which the challenges of adopting online education during the COVID-19 pandemic are included. Second, even though several MCDM problems have been developed under the environment of HFSs, there is no study on developing the integrated framework with Step-wise Weight Assessment Ratio Analysis (SWARA) method and Multi-Objective Optimization based on Ratio Analysis Plus Full multiplicative Form (MULTIMOORA) approaches over hesitant fuzzy information. Third, there is no study in which HF-SWARAMULTIMOORA was employed to estimate the criteria weights and rank the institutions for adapting online education to control the pandemic spread of COVID-19, especially in Iran. To this end, the present study aims:

- To identify the main challenges of adopting online education during the COVID-19 pandemic

- To propose an integrated framework is introduced within the context of HFSs to handle the complex MCDM problems

- To determine the most critical challenges of adapting online education during the COVID-19 outbreak using the SWARA model

- To rank higher education institutions during the COVID-19 outbreak using The MULTIMOORA method 
- To express the applicability and usefulness of the developed integrated framework within the HFSs context through an empirical study

- To validate the results through comparative analysis with existing methods.

\section{Literature review}

\subsection{Status of online education during COVID-19 pandemic}

A majority of individuals can easily access the new knowledge and work remotely through online platforms. To be specific, online education comprising learning management systems, mobile learning, and so on can engage different students (Romero-Rodríguez et al. 2020). However, the course developers and the governments have been faced the challenges of constructing a learning atmosphere in which the learning process and students' assessment happens appropriately, while it is both content and community-centered (Anderson 2008). Furthermore, there is no standard mean of online learning, nor a specific framework, dictating the type of communication, which is suitable for all learners in different fields. Instead, Instructors should extend their knowledge and skills to respond to curriculum and students' needs by extending a set of online education tasks adaptable to various student needs. Surprisingly, online education has become an inseparable part of the education system, especially in training and higher education (Anderson 2008). Although the number of institutions that have adapted their education system with online platforms is not noticeable, the number of students and higher education providers attracted to online education is growing exponentially, especially during the COVID-19 pandemic (Anderson 2008; Huang 2020).

Zapalska and Brozik (2006) mentioned an interest in online education has been increasing in recent years by the advent and development of the internet worldwide so that it was predicted that the education landscape would be changed (Zapalska and Brozik 2006), while COVID-19 boost the utilizing the online platforms these days (Cecilio-Fernandes et al. 2020). However, since online education is dependent on new technologies has been changing rapidly so that the effectiveness of online education may be over shadowed by technological innovation. Furthermore, there are many different learning styles for students (Zapalska and Brozik 2006). For instance, some may learn more effectively by listening and watching, while others may learn by reading or performing some physical activities so that considering variant styles of learning in online education is vital. Nevertheless, due to online education limitations, such as not having practical sessions (Longhurst et al. 2020), it is challenging for adapting online education with learning styles.

Besides, it is reported that near 1.723 billion students in the world have been influenced owing to school closures in regards to the pandemic, while teachers, parents, and universities have been affected as well (Mustafa 2020). As mentioned, many universities have shown interest in using online education to resume their classes remotely during the COVID-19 pandemic. In China, for instance, near 2163 and 1824 online courses have been launched for undergraduate and graduate students, respectively, in the perking university to operate teaching typically, while near 45,000 students have to stay at their homes or dorms (Bao 2020). However, the Chinese government never set country-wide rules in universities' closures, while other countries such as the US, Brazil, Canada, and Russia do the same (Crawford et al. 2020). Although some universities' opportunities to boost their online courses during COVID-19 crises (Vlachopoulos 2020), some universities in some 
countries such as Jordan encounter many challenges. For example, in Jordan, the number of technology solutions supporting online teaching is low. This is due to the fact; there is not enough time to design a coordinated strategy for dealing with these crises in the world (Crawford et al. 2020).

Furthermore, some scholars have been researched in the field of online education during the COVID-19 pandemic. (Zayapragassarazan 2020) researched to investigate the strategies for engaging students in online medical education. He concluded that behavioral indicators should have effective online education, especially in medical education. There is a wide variety of activities that both instructors and students can do, including observational learning behaviors and Practical learning behaviors. (Dwidienawati and Musrin 2020) carried out research to find the factors affecting e-learning performance and satisfaction regarding students who have to attend online education due to COVID-19. The results indicated that service quality is one factor that has a considerable effect on students' satisfaction. (Longhurst et al. 2020) used Strength, Weakness, Opportunity, Threat (SWOT) analysis to find the challenges and opportunities of online education in anatomical education in the UK and Ireland. The results indicated that there are seven opportunities, including the development of new online resources, academic collaboration, free access to online resources, incorporation of mix learning in development, working remotely, while there are nine challenges, including issues with assessment, time constraints of bsuspensionody donor program.

\subsection{Challenges of adapting online education in response to COVID-19 pandemic}

Higher education institutions have been challenged by students' growing interest in online education to redesign their pedagogical, organizational, academic, and cultural structures to employ new learning and teaching methods (Howell et al. 2004). Similarly, both instructors' roles and the nature of teaching have altered due to the diversity of online courses offered by different institutions (Bennett and Lockyer 2004). On the other hand, a majority of students have faced many challenges during the COVID-19 pandemic. In this section, the challenges of adapting online education in response to the COVID-19 pandemic include systemic challenges, pedagogical challenges, and psychological challenges.

\subsubsection{Systemic challenges}

Systemic challenges are related to all challenges which stem from the weakness of technological systems, economic, policies, etc. The systemic challenges comprise a lack of technical support, lack of online technologies, cost constraints, and lack of policies for online courses. In the following, the mentioned systemic challenges are presented.

\subsubsection{Lack of technical support}

Students may become frustrated due to technical problems, while it can affect learning negatively. On top of that, reliable and accessible technical support is vital in assisting learners so that organizations and institutions should develop appropriate technical support (Liu et al. 2005). Also, appropriate technical support affects students' participation in online programs effectively (Shamsy 2014). Nevertheless, it is difficult to provide technical support, mostly when students' vast verity should be supported in the COVID-19 epidemic (Longhurst et al. 2020). 


\subsubsection{Lack of online technologies}

Although the advantages of online education due to technology development, Technological challenges are considered fundamental challenges in the online education system (Arbaugh 2005). Many difficulties may arise due to the existing limitation in terms of the technical capability of the platforms and software (Gillett-Swan 2017). Furthermore, the main technological challenge during the COVID-19 pandemic maybe the lack of appropriate platforms for online education. For example, it is reported that almost $10 \%$ of the learners have an appropriate platform for online education in University Grants Commission (UGC), while near $62 \%$ of learners were utilizing WhatsApp to share academic inputs (Babu and Jayakumar 2020).

\subsubsection{Cost constraints}

Online education costs are different from traditional education, though it is believed that online education can reduce costs (Bates and San Francisco 2001). Two types of costs should be considered, including the cost of online education technologies, the cost of distributing and receiving knowledge (Rumble 2004). As mentioned, online technologies are needed to provide online education so that institutions, instructors, and students should provide appropriate technologies having a considerable cost for them. Besides, it cost institutions to provide web-based materials, while distributing and receiving these materials through the internet have cost for institutions and students, respectively (Rumble 2004). Therefore, cost constraints is an important challenge in online education, while almost many students go for online education doe to COVID-19 pandemic so that it may cause a rise in online education cost for institutions, students and even the government.

\subsubsection{Lack of policies for online education}

Having a clear understanding of the expectations in an online class form, both instructors and students are necessary; therefore, clear policies and standards are required (Lloyd et al. 2012). Online education policies also comprise various issues, including policies related to students' privacy, email, and assignments. On top of that, the appropriate policies related to online discussion, software standards, and intellectual property (Waterhouse and Rogers 2004). Therefore, it is undeniable that policymakers in institutions or the government should set good policies to determine online classes (Lloyd et al. 2012).

\subsubsection{Pedagogical challenges}

There are some challenges in learning, such as reduced quality of resources, or lack of teaching experience, and so on, presented in this section. The pedagogical challenges comprise the quality of materials, lack of experience, online assessment, student engagement, and practical classes. In the following, the mentioned pedagogical challenges are presented. 


\subsubsection{Quality of materials}

Esfijani (2018) mentioned that one of the most critical indicators in online education quality is resource quality. Quality of resources can be evaluated by the quality of their content, course structure, and learning management (Esfijani 2018). To be more specific, courses' materials should be well-designed, accessible, user friendly, interactive, and so on (Esfijani 2018). However, during the COVID-19 pandemic, it is arduous to design a course properly due to the time constraints and the lack of experience, while the experience of online education should be rich both affectively and intellectually (Kebritchi et al. 2017; Longhurst et al. 2020).

\subsubsection{Lack of experience}

Planning and preparing course materials is one of the essential responsibilities for instructors, while they may encounter various challenges in terms of producing and adjusting new materials from traditional classes to online classes ( $\mathrm{Li}$ and Irby 2008). Also, institutions may never provide training and support for instructors so that courses' content transition from traditional to online may be challengeable (Kebritchi et al. 2017); furthermore, since online education depends on technology so that the quality of pedagogical experiences in online education are influenced by technology (Evans et al. 2008).

\subsubsection{Online assessment}

Longhurst et al. (2020) mentioned that almost 30\% of institutions do not have pre-existing summative assessments concerning useful content, while over $40 \%$ of universities have been canceled their assessment in response to COVID-19 (Longhurst et al. 2020). Also, online education's assessment process is entirely different since this process happens not in a physical space and both instructors and students are far from each other. Simultaneously, (Jacobs 2014) mentioned that assessment methods that determine students' progress are crucial in the online education system (Kebritchi et al. 2017).

\subsubsection{Student engagement}

It is believed that student engagement may be reduced in online education due to the existed differences in the learning environment and course materials (Jaggars 2014). For instance, many instructors may use a long video to teach; however, it is considered a potential threat in online education, negatively affecting student engagement (Longhurst et al. 2020). Also, the massification of higher education through online education might impact the students' motivation (Trow 2007) so that it is challenging to maintain students' engagement in online classes during the COVID-19 pandemic since most students have to intend online classes (Longhurst et al. 2020).

\subsubsection{Lack of practical classes}

Some disciplines have practical sessions in their semester curriculum, while it seems to be impossible to have these types of classes in online education. For instance, near 
half of the universities offering anatomical classes are concerned about cadaveric exposure and practical sessions (Longhurst et al. 2020). On top of that, practical sessions create a window of opportunities for students to retain knowledge, and it affects students' engagement so that the lack of practical sessions may decrease the efficiency of the learning process (Spiceland et al. 2015).

\subsubsection{Psychological challenges}

Psychological challenges stem from those factors which have effects mentally or emotionally. Psychological challenges comprise lockdown pressure during the COVID-19 pandemic, time pressure, and fear of digitalization. In the following, the mentioned psychological challenges are presented in detail.

\subsubsection{Lockdown pressure}

Kazmi et al. (2020) concluded that psychological distress had been created among people due to the Covid-19 pandemic. Since they have been forced to stay at home owing to the existed restrictions due to COVID-19. People may feel a lack of control in their everyday life and routines since it is admitted they are going through a disaster owing to COVID-19 lockdown. As a result, the youth encounter uncertainty regarding their professional life or learning process since they are afraid of getting infected (Kazmi et al. 2020). Also, it is reported that people think that they cannot perform their duty correctly or deal with problematic situations in crucial time so that it may reduce their motivation having adverse effects on different aspects of their life, including education (Jadhav 2020).

\subsubsection{Time pressure}

The materials' quality and effectiveness may be affected by time constraints due to the fast pace of COVID-19 spreading. At the same time, it is reported that a majority of universities, near 60 percent during the COVID-19 pandemic, were concerned about time pressure involved in preparing new materials for online classes to take the place of lectures and practical sessions (Longhurst et al. 2020). Furthermore, instructors should take much time to learn how to utilize technologies in online education, while creating materials for online education may take three times as much work compared to face-to-face education (Gewin 2020).

\subsubsection{Fear of digitalization}

Students may feel disconnected and isolated in online education affecting learning (McInnerney and Roberts 2004). The sense of identity among students influenced by learning's community since students co-create their identity through interacting socially within a community (Koole 2014). Thus, to build knowledge effectively, improving the sense of belonging is vital, while it may be challenging in online education (Kebritchi et al. 2017). Although digitalization in higher education gets instructors and students this chance to communicate virtually (Strielkowski et al. 2020), most of them, even the youth who are often online, are not ready for online education. Therefore, they would rather be in a faceto-face class than in a virtual one (Strielkowski 2020). (Table 1) provides information about the challenges of adapting online education during the COVID-19 pandemic. 


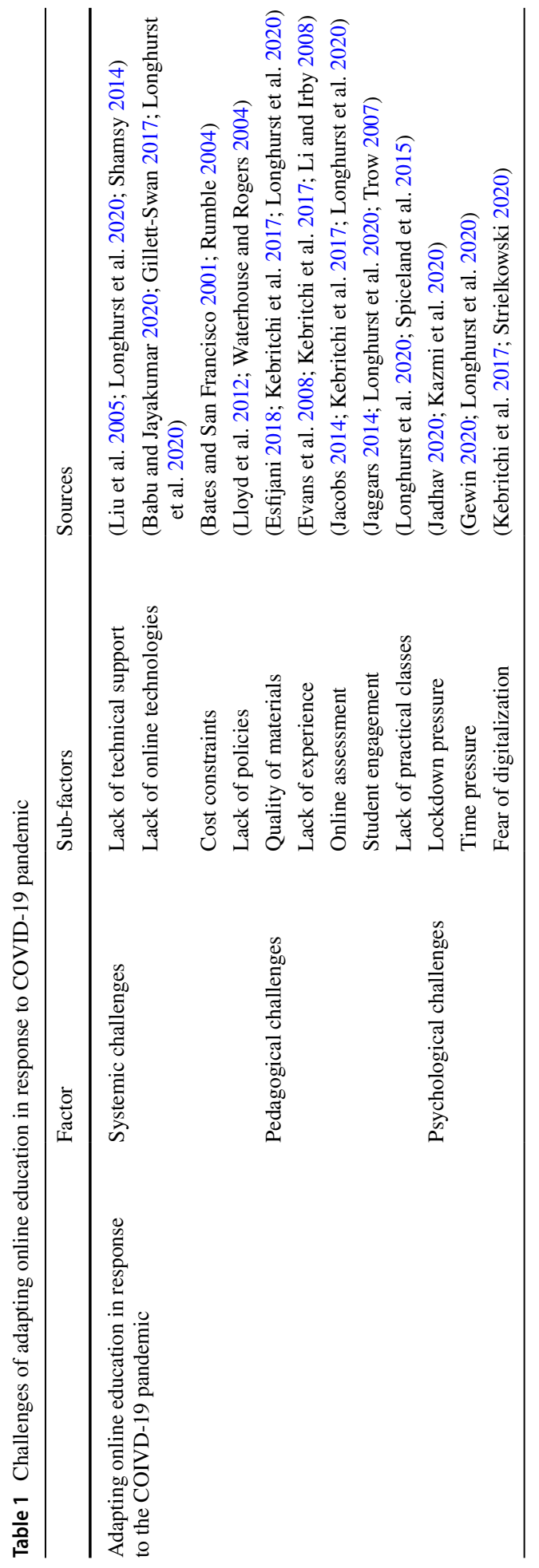




\section{Research method}

\subsection{Preliminaries}

In the decision-making procedure, the Decision-Makers (DMs) might assess the belongingness degree (BD) of an object to a set of various distinct degrees in numerous real-life circumstances because of their attention, time restrictions, and deficiency of information. For example, suppose a DM group is expressed in offering the $\mathrm{BD}$ of individual opinion to an adult age group. In that case, the first one wishes 0.55 , another 0.60 , and the last one does not recommend the BD due to the time restrictions and deficiency of knowledge/information/data. To handle this concern, Torra (2010) and Torra and Narukawa (2009) pioneered the idea of HFSs, which offers the BD to comprise several different evaluation degrees (Torra 2010; Torra and Narukawa 2009). As the extension of fuzzy sets (FSs), HFSs are recognized as useful and eminent environments to tackle real-life situations' ambiguity. It is represented by a BD and signified by a set of possible degrees. Recently, it is worth mentioning that the HFSs have powerfully related to the existing FSs, namely, Intuitionistic Fuzzy Sets (IFSs) (Atanassov 1986), Type-2 Fuzzy Sets (T2FSs) (Zadeh 1975), Fuzzy Multi-Sets (FMSs) (Yager 1986). Several MCDM techniques have been developed in the HFSs context (Li et al. 2020; Mishra et al. 2019a). Mishra et al. (2019a) proposed a Shapley function-based HF-Complex Proportional Assessment (COPRAS) approach to handle the correlative MCDM problems for HFSs. Xu and Zhang (2019) presented an outline of group decision-making implementations from three different aspects of HFSs (Zhao et al. 2017). Mishra et al. (2019b) suggested an integrated HF-WASPAS method to choose an ideal green supplier for HFSs (Mishra et al. 2019b).

Definition 1 (Torra 2010): Given a discourse set $Y$ A HFS $R$ on $Y$ is defined by the function $\hbar_{R}(y)$ implemented to $Y$, which maps a finite subset of [0,1], is denoted by.

$$
R=\left\{\left\langle y, \hbar_{R}(y)\right\rangle: y \in Y\right\},
$$

where $\hbar_{R}(y)$ denotes a set of various degrees in [0,1], illustrating the feasible membership degrees of an object $y \in Y$ to $R$. For ease of simplicity, $\hbar_{R}(y)$ is defined as the hesitant fuzzy number (HFN), which holds $\hbar_{R}(y)=\left\{l: l \in \hbar_{R}(y)\right\}$.

Definition 2. (Torra 2010; Xia and Xu 2011): Assume that $\hbar, \hbar_{1}, \hbar_{2} \in \operatorname{HFNs}(Y)$, then the fundamental laws on HFNs are discussed as below:

(i). $\hbar^{c}=\cup_{t \in \hbar}\{1-\imath\}$;

(ii). $\hbar_{1} \cup \hbar_{2}=\cup_{l_{1} \in \hbar_{1}, l_{2} \in \hbar_{2}} \max \left\{l_{1}, l_{2}\right\}$;

(iii). $\hbar_{1} \cap \hbar_{2}=\cap_{l_{1} \in \hbar_{1}, l_{2} \in \hbar_{2}} \min \left\{l_{1}, l_{2}\right\}$;

(iv). $\lambda \hbar=\cup_{l \in \hbar}\left\{1-(1-l)^{\lambda}\right\}, \lambda>0$;

(v). $\hbar^{\lambda}=\cup_{l \in \hbar}\left\{l^{\lambda}\right\}, \lambda>0$;

(vi). $\hbar_{1} \oplus \hbar_{2}=\cup_{l_{1} \in \hbar_{1}, l_{2} \in \hbar_{2}}\left\{l_{1}+l_{2}-l_{1} l_{2}\right\}$;

(vii). $\hbar_{1} \otimes \hbar_{2}=\cup_{l_{1} \in \hbar_{1}, l_{2} \in \hbar_{2}}\left\{l_{1} l_{2}\right\}$.

Definition 3: In HFS, the score function of the element $h$ is described as.

$$
\mathbb{S}(\hbar)=\frac{1}{g_{\hbar}} \sum_{l \in \hbar} l
$$


Here, $g_{\hbar}$ denotes the number of objects in $\hbar$. For any HFNs $\hbar_{1}$ and $\hbar_{2}$, if $\mathbb{S}\left(\hbar_{1}\right)>\mathbb{S}\left(\hbar_{2}\right)$, then $\hbar_{1}>\hbar_{2}$; if $\mathbb{S}\left(\hbar_{1}\right)=\mathbb{S}\left(\hbar_{2}\right)$, then $\hbar_{1}=\hbar_{2}$.

In various cases, the above-discussed comparison law does not hold good. To handle this concern, (Liao et al. 2014) initiated a variance concept to compare the HFSs.

For an HFE $\hbar$, the variance function of the element $\hbar$ is given by

$$
\vartheta(\hbar)=\frac{1}{g_{\hbar}} \sqrt{\sum_{l_{i}, l_{j} \in \hbar}\left(l_{i}-l_{j}\right)^{2}} .
$$

Based on $\mathbb{S}(\hbar)$ and $\vartheta(\hbar)$, a systematic procedure is derived as follows:

If $\mathbb{S}\left(\hbar_{1}\right)>\mathbb{S}\left(\hbar_{2}\right)$, then $\hbar_{1}>\hbar_{2}$;

If $\mathbb{S}\left(\hbar_{1}\right)=\mathbb{S}\left(\hbar_{2}\right)$, then.

if $\vartheta\left(\hbar_{1}\right)>\vartheta\left(\hbar_{2}\right)$, then $\hbar_{1}<\hbar_{2}$;

if $\vartheta\left(\hbar_{1}\right)=\vartheta\left(\hbar_{2}\right)$, then $\hbar_{1}=\hbar_{2}$.

Definition 4. (Liao et al. 2014; Xia and Xu 2011): Consider a set of HFNs $H=\left\{\hbar_{1}, \hbar_{2}, \ldots, \hbar_{n}\right\}$, then the Hesitant Fuzzy Weighted Average (HFWA) and geometric (HFWG) operators are defined as.

$$
\begin{gathered}
\operatorname{HFWA}\left(\hbar_{1}, \hbar_{2}, \ldots, \hbar_{n}\right)=\bigoplus_{j=1}^{n} \omega_{j} \hbar_{j}=\cup_{l_{1} \in \hbar_{1}, l_{2} \in \hbar_{2}, \ldots, l_{n} \in \hbar_{n}}\left\{1-\prod_{j=1}^{n}\left(1-\imath_{j}\right)^{\omega_{j}}\right\}, \\
\operatorname{HFWG}\left(\hbar_{1}, \hbar_{2}, \ldots, \hbar_{n}\right)=\bigotimes_{j=1}^{n}\left(\hbar_{j}\right)^{\omega_{j}}=\cup_{l_{1} \in \hbar_{1}, l_{2} \in \hbar_{2}, \ldots, l_{n} \in \hbar_{n}}\left\{\prod_{j=1}^{n}\left(l_{j}\right)^{\omega_{j}}\right\} .
\end{gathered}
$$

Definition 5: Let $R \in \operatorname{HFS}(Y)$. Then, an entropy measure defined by (Mishra et al. 2019a), is as follows:

$$
e(R)=\frac{1}{n} \sum_{i=1}^{n}\left[\frac{1}{l_{y}} \sum_{j=1}^{l_{y}}\left\{\frac{\hbar_{R}^{\sigma(j)}\left(y_{i}\right) \wedge \hbar_{R}^{\sigma\left(l_{z}-j+1\right)}\left(y_{i}\right)}{\hbar_{R}^{\sigma(j)}\left(y_{i}\right) \vee \hbar_{R}^{\sigma\left(l_{z}-j+1\right)}\left(y_{i}\right)}\right\}\right] .
$$

Definition 6: Let $R, S \in H F S(Y)$. Then, an entropy measure defined by (Xia and $\mathrm{Xu} 2011$ ), is as follows:

$$
D(R, S)=\frac{1}{n} \sum_{i=1}^{n}\left[\frac{1}{l_{y}} \sum_{j=1}^{l_{y}}\left|\hbar_{R}^{\sigma(j)}\left(y_{i}\right)-\hbar_{S}^{\sigma(j)}\left(y_{i}\right)\right|\right] .
$$

\section{Proposed hesitant fuzzy SWARA-MULTIMOORA method}

This section develops a novel decision-making framework, named hesitant fuzzy SWMOORA (HF-SWARA-MULTIMOORA), to tackle the MCDM problems within the HFSs context. For the development of the proposed MULTIMOORA method, the notions and operations of the HFNs, score function, and entropy measure are utilized within the framework of HFSs. The computation process of the developed approach is presented by. 


\subsection{Step 1: Originate the option and criteria}

A set of $\ell$ DEs $\left\{B_{1}, B_{2}, \ldots, B_{\ell}\right\}$ determines the sets of ' $m$ ' alternative $\left\{U_{1}, U_{2}, \ldots, U_{m}\right\}$ and 'n' criteria $\left\{T_{1}, T_{2}, \ldots, T_{n}\right\}$, respectively. Assume that $Z=\left(z_{i j}^{(k)}\right)_{m \times n}, i=1(1) m, j=1(1) n$ be the Hesitant Fuzzy Decision Matrix (HF-DM) specified by $k^{\underline{m} \times n}$ expert, where $z_{i j}^{(k)}$ means the assessment of an option $U_{i}$ concerning a criterion $T_{j}$ in terms of HFNs for $k^{\text {th }}$ expert.

\subsection{Step 2: Determine crisp DMs weights}

The formula for the determination of $k^{\text {th }}$ expert weight is as follows:

$$
\lambda_{k}=\frac{\left(1-e\left(\hbar_{k}\right)\right)}{\sum_{k=1}^{l}\left(1-e\left(\hbar_{k}\right)\right)}, \quad k=1(1) l .
$$

\subsection{Step 3: Calculate the aggregated HF-DM (AHF-DM)}

In MCDM, it is essential to aggregate the individual matrices into a single decision matrix. To aggregate the matrices, the HFWA operator is applied and then $P=\left(\xi_{i j}\right)_{m \times n}$ is the required aggregated $\mathrm{HF}$-decision matrix where

$$
\xi_{i j}=\cup_{l_{1} \in \hbar_{1}, l_{2} \in \hbar_{2}, \ldots, l_{n} \in \hbar_{n}}\left\{1-\prod_{k=1}^{\ell}\left(1-z_{i j}^{(k)}\right)^{\lambda_{k}}\right\} .
$$

\subsection{Step 4: Evaluating the criteria weights using the SWARA method}

Keršuliene et al. (2010) studied a novel SWARA method for the computation of subjective criteria weights in the process of MCDM (Keršuliene et al. 2010). This approach has lesser computational difficulty in comparison with other weight-determining approaches. Just a while ago, the SWARA method has widely been utilized in several MCDM problems. (Rani et al. 2020) studied a hybrid method by employing SWARA and VlseKriterijumska Optimizacija I Kompromisno Resenje in Serbian (VIKOR) approaches to deal with eco-industrial thermal power plant selection problem within the single-valued neutrosophic fuzzy environment. (Mishra et al. 2020) presented an integrated approach using SWARA and COPRAS approaches for the selection of bioenergy production technology alternatives. (Rani et al. 2020) developed an MCDM framework with SWARA and VIKOR methods for solving the Solar Panel Selection (SPS) problem within the Pythagorean fuzzy environment. (Mardani et al. 2020) proposed integrated SWARA and WASPAS under the hesitant fuzzy environment to evaluate the digital health interventions to control the COVID-19 pandemic.

Ranking the criteria is the first step of The SWARA method and compares pairwise direct highest to lowest-ranking criterion. Subsequently, a relative coefficient should be calculated. Next, the weight which is required for dealing with MCDM problems should be evaluated. In the following, the steps of the criteria weight's evaluation using SWARA are presented: 
Step 4.1: Compute the crisp numbers. Score degrees $\mathbb{S}\left(\xi_{k j}\right)$ of HFNs are computed based on Eq. (2).

Step 4.2: Determine the criterion ranking order. According to DE's choice, all criteria are arranged, from the best to the slightest essential degrees of criteria.

Step 4.3: Assess the degree of comparative importance. The comparative importance is determined from the second place's criteria, and the succeeding importance degree is determined to compute the criteria differences.

Step 4.4: Evaluate the comparative coefficient. The number $k_{\mathrm{j}}$ is discussed as

$$
k_{j}= \begin{cases}1, & s_{j}+1 \\ s_{j}+1, & j>1\end{cases}
$$

wherein $s_{\mathrm{j}}$ denotes the comparative significance of score value (Keršuliene et al. 2010). Step 4.5: Compute the criteria weight. The value of $p_{\mathrm{j}}$ is estimated by

$$
p_{j}=\left\{\begin{array}{l}
1, \quad j=1 \\
\frac{k_{j-1}}{k_{j}}, j>1
\end{array} .\right.
$$

Step 4.6: Compute the weighted degree. By using the recalculated values $p_{\mathrm{j}}$, the criteria weights are estimated as

$$
w_{j}=\frac{p_{j}}{\sum_{j=1}^{n} p_{j}} .
$$

Next, the Multi-Objective Optimization based on Ratio Analysis (MOORA) pioneered by (Brauers and Zavadskas 2006), is one of the practical and renowned MCDM methods, which contains Ratio System (RS) and Reference Point (RP) model. To increase the MOORA framework's robustness, (Brauers and Zavadskas 2010) developed a new approach and named as MULTIMOORA, which contains three components: the RS, RP, and the Full Multiplicative Form (FMF) procedure. As compared to Analytic Hierarchy Process (AHP), Technique for Order of Preference by Similarity to Ideal Solution (TOPSIS), VIKOR, Preference Ranking Organization METHod for Enrichment of Evaluations (PROMETHEE), Linear Programming Technique for Multidimensional Analysis of Preference (LINMAP) and ELimination Et Choice Translating REality (ELECTRE), the MULTIMOORA framework has more superior stability, easy mathematical expressions, less computation time and strong robustness (Brauers and Zavadskas 2012). Based on the MULTIMOORA approach's advantages, several authors have focused their attention on the developments and applications of the MULTIMOORA framework (Liao et al. 2019; Zhang et al. 2019).

\subsection{Step 5: Compute the rank of the options-based on the RS procedure}

The given sub steps can articulate the preference order of the options and the assessment of the best option-based on RS procedure:

Step 5.1: Estimate $Y_{i}^{+}$and $Y_{i}^{-}$by applying Hesitant Fuzzy Weighted Aggregation Operator (HFWAO) as 


$$
\begin{aligned}
& Y_{i}^{+}=\cup_{l_{1} \in \hbar_{1}, l_{2} \in \hbar_{2}, \ldots, l_{n} \in \hbar_{n}}\left\{1-\prod_{j \in T_{b}}\left(1-\xi_{i j}\right)^{w_{j}}\right\}, \\
& Y_{i}^{-}=\cup_{l_{1} \in \hbar_{1}, l_{2} \in \hbar_{2}, \ldots, l_{n} \in \hbar_{n}}\left\{1-\prod_{j \in T_{n}}\left(1-\xi_{i j}\right)^{w_{j}}\right\} .
\end{aligned}
$$

where $Y_{i}^{+}$and $Y_{i}^{-}$are the significance of the option $i$ achieved-based on benefit-type and cost-type criteria, respectively.

Step 5.2: Calculate the $y_{i}^{+}$and $y_{i}^{-}$by utilizing Eq. (2) as

$$
y_{i}^{+}=\mathbb{S}\left(Y_{i}^{+}\right) \text {and } y_{i}^{-}=\mathbb{S}\left(Y_{i}^{-}\right)
$$

Step 5.3: Assess the overall significance for each option and is given by

$$
y_{i}=y_{i}^{+}-y_{i}^{-} .
$$

Step 5.4: Evaluate the ranking order of the options and choose the best option.

\subsection{Step 6: Compute the rank of the options-based on the RP procedure.}

The rank of the options and the choice of the best option based on the RP procedure can be discussed as follows:

Step 6.1: Choose the RP. Here, each coordinate of the reference point $r^{*}=\left\{r_{1}^{*}, r_{2}^{*}, \ldots, r_{n}^{*}\right\}$ is an $\mathrm{HFN} r_{j}^{*}$ whose values are determined as follows:

$$
r_{j}^{*}=\left\{\begin{array}{l}
\max _{i} \xi_{i j}, \text { for benefit criterion } T_{b} \\
\min _{i} \xi_{i j}, \text { for cost criterion } T_{n}
\end{array} \text { for } j=1(1) n .\right.
$$

Step 6.2: Calculate the differences from each option to the given coordinates of the RP as follows:

$$
D_{i j}=w_{j}\left(D\left(\xi_{i j}, r_{j}^{*}\right)\right) \text {, }
$$

where $D_{i j}$ is the discrimination measure and is computed by Eq. (7).

Step 6.3: Estimate the maximum distance of each option and is given by

$$
d_{i}=\max _{j} D_{i j} ; i=1(1) m .
$$

Step 6.4: Evaluate the ranking order of the options and choose the best option.

\subsection{Step 7: Compute the rank of the options-based on the FMF procedure.}

The rank of the options and the choice of the best option based on the FMF procedure can be discussed as follows: 
Sub-step 7.1: Estimate $A_{i}$ and $B_{i}$ by applying HFWGO as

$$
\begin{aligned}
& A_{i}=\cup_{l_{1} \in \hbar_{1}, l_{2} \in \hbar_{2}, \ldots, l_{n} \in \hbar_{n}}\left\{\prod_{j \in T_{b}}\left(\xi_{i j}\right)^{w_{j}}\right\}, \\
& B_{i}=\cup_{l_{1} \in \hbar_{1}, l_{2} \in \hbar_{2}, \ldots, l_{n} \in \hbar_{n}}\left\{\prod_{j \in T_{n}}\left(\xi_{i j}\right)^{w_{j}}\right\},
\end{aligned}
$$

where $A_{i}$ and $B_{i}$ are HFNs.

Sub-step 7.2: Calculate $\alpha_{i}$ and $\beta_{i}$ by using the score function as follows:

$$
\alpha_{i}=\mathbb{S}\left(A_{i}\right) \text { and } \beta_{i}=\mathbb{S}\left(B_{i}\right) .
$$

Sub-step 7.3: Determine the overall utility for each alternative as follows:

$$
u_{i}=\frac{\alpha_{i}}{\beta_{i}}
$$

Sub-step 7.4: Evaluate the ranking order of the options and choose the best option.

\subsection{Step 8: Determine the final ranking order of the alternatives.}

Normalizing the RS, RP and FMF scores of options by vector normalization, we obtain $y_{i}^{*}$, $d_{i}^{*}$, and $u_{i}^{*}$, respectively. The assessment value of alternative by Improved Borda Rule ( $\mathrm{Wu}$ et al. 2018) is obtained by

$$
I_{B}\left(P_{i}\right)=y_{i}^{*} \cdot \frac{m-\rho\left(y_{i}^{*}\right)+1}{(m(m+1) / 2)}-d_{i}^{*} \cdot \frac{\rho\left(d_{i}^{*}\right)}{(m(m+1) / 2)}+u_{i}^{*} \cdot \frac{m-\rho\left(u_{i}^{*}\right)+1}{(m(m+1) / 2)} ; \quad i=1(1) m .
$$

where $y_{i}^{*}=\frac{y_{i}}{\sqrt{\sum_{i=1}^{m}\left(y_{i}\right)^{2}}}$, and $\rho\left(y_{i}^{*}\right), \rho\left(d_{i}^{*}\right)$, and $\rho\left(u_{i}^{*}\right)$, are the final rank set of RS, RP and FMF approach, respectively. The best alternative has the maximum value of $I_{B}\left(P_{i}\right)$.

\section{Results}

Tables 2 and 3 present the Linguistic Values (LVs) and their corresponding HFNs for the rating of the relative importance of criteria and options in terms of the MCDM problem, respectively. Due to the lack of information, time limitation, and qualitative nature of considered criteria, it is effortless for the DEs to lucid their judgments with linguistic values (Mishra et al. 2019b).

Let us consider the weights of DEs in the forms of LVs and are given as $\{\mathrm{H}, \mathrm{VH}, \mathrm{M}\}$. Therefore, by using Table 2, Eq. (6) and Eq. (8), the crisp weights $\lambda_{k}: 1,2,3$ of DEs are obtained as $\lambda 1=0.3349, \lambda 2=0.3456, \lambda 3=0.3195$. The HF-decision matrices given by DEs $B_{k}(k=1,2,3)$ can be obtained in Table 4 in the form of $Z=\left(z_{i j}^{(k)}\right)_{6 \times 12}, i=1(1) 6, j=1(1) 12$ given as. 
Table 2 LVs for the significance of criteria and DEs

\begin{tabular}{lllll}
\hline LVs & HFNs & \multicolumn{2}{l}{ DEs risk preference } \\
\cline { 3 - 5 } & & Pessimist & Moderate & Optimist \\
\hline Very high (VH) & {$[0.85,1.00]$} & 0.85 & 0.925 & 1.00 \\
High (H) & {$[0.70,0.85]$} & 0.70 & 0.775 & 0.85 \\
Medium (M) & {$[0.55,0.70]$} & 0.55 & 0.625 & 0.70 \\
Low (L) & {$[0.40,0.55]$} & 0.40 & 0.475 & 0.55 \\
Very low (VL) & {$[0.25,0.40]$} & 0.25 & 0.325 & 0.40 \\
\hline
\end{tabular}

Table 3 Linguistic variables for the importance of criteria and options

\begin{tabular}{lllll}
\hline LVs & HFNs & \multicolumn{2}{l}{ DEs risk preference } \\
\cline { 3 - 5 } & & Pessimist & Moderate & Optimist \\
\hline Extremely preferable (EP) & {$[0.90,1.00]$} & 0.90 & 0.95 & 1.00 \\
Strong preferable (SP) & {$[0.75,0.90]$} & 0.75 & 0.825 & 0.90 \\
Preferable (P) & {$[0.60,0.75]$} & 0.60 & 0.675 & 0.75 \\
Moderately preferable (MP) & {$[0.50,0.60]$} & 0.50 & 0.55 & 0.60 \\
Moderate (M) & {$[0.40,0.50]$} & 0.40 & 0.45 & 0.50 \\
Moderately undesirable (MU) & {$[0.30,0.40]$} & 0.30 & 0.35 & 0.40 \\
Undesirable (U) & {$[0.20,0.30]$} & 0.20 & 0.25 & 0.30 \\
Strong undesirable (SU) & {$[0.10,0.20]$} & 0.10 & 0.15 & 0.20 \\
Extremely undesirable (EU) & {$[0.00,0.10]$} & 0.00 & 0.05 & 0.10 \\
\hline
\end{tabular}

The judgment provided by three DEs has been aggregated utilizing Eq. (9), Table 3 and then create AHF-D matrix $P=\left(\xi_{i j}\right)_{6 \times 12}$, taking into effect the importance of individual $\mathrm{DE}$ and are provided in Table 5.

For the SWARA procedure, the character of the experts is a significant part of the assessment of criteria weights. The expert gives the preferences of every criterion-based on their implicit knowledge and experiences (see Table 6). From Table 7, the criterion with the highest significance degree is depicted as the first rank, and the criterion with a less significant degree is mentioned as the last place. Hence, the subjective weights of criteria are computed-based on Eqs. (10)-(12) and Table 7, given as

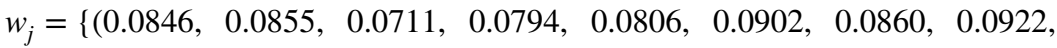

$$
\begin{aligned}
& 0.0866,0.0802,0.0869,0.0767)\}
\end{aligned}
$$

The ratio system model of HF-SWARA-MULTIMOORA approach for the universities is evaluated by Eq. (13)-Eq. (16) and shown in Table 8.

The results of the hesitant fuzzy reference point objective for the considered universities are estimated by using Eq. (17)-Eq. (19) and presented in Table 9

$$
r_{j}^{*}=\{0.310,0.299,0.404,0.304,0.560,0.427,0.670,0.783,0.677,0.499,0.639,0.493\} .
$$

The hesitant fuzzy full multiplicative form objective based on distance measure for the considered universities is computed by using Eq. (20)-Eq. (23) and given in Table 10. 
Table 4 Linguistic values for criteria performance given by DEs

\begin{tabular}{|c|c|c|c|c|c|c|c|}
\hline Criteria & DEs & $\mathrm{U}_{1}$ & $\mathrm{U}_{2}$ & $\mathrm{U}_{3}$ & $\mathrm{U}_{4}$ & $\mathrm{U}_{5}$ & $\mathrm{U}_{6}$ \\
\hline \multirow[t]{3}{*}{$\mathrm{T}_{1}$} & $\mathrm{~B}_{1}$ & SU & SU & $\mathrm{U}$ & $\mathrm{P}$ & SU & $\mathrm{P}$ \\
\hline & $\mathrm{B}_{2}$ & $\mathrm{P}$ & SU & $\mathrm{M}$ & MP & $\mathrm{P}$ & U \\
\hline & $\mathrm{B}_{3}$ & $\mathrm{P}$ & MP & $\mathrm{M}$ & $\mathrm{P}$ & M & SU \\
\hline \multirow[t]{3}{*}{$\mathrm{T}_{2}$} & $\mathrm{~B}_{1}$ & M & $\mathrm{U}$ & $\mathrm{P}$ & $\mathrm{M}$ & $\mathrm{P}$ & $\mathrm{SU}$ \\
\hline & $\mathrm{B}_{2}$ & $\mathrm{P}$ & $\mathrm{MU}$ & $\mathrm{P}$ & $\mathrm{M}$ & $\mathrm{M}$ & MP \\
\hline & $\mathrm{B}_{3}$ & $\mathrm{P}$ & $\mathrm{U}$ & $\mathrm{MU}$ & $\mathrm{P}$ & $\mathrm{P}$ & $\mathrm{U}$ \\
\hline \multirow[t]{3}{*}{$\mathrm{T}_{3}$} & $\mathrm{~B}_{1}$ & $\mathrm{U}$ & M & M & MP & $\mathrm{P}$ & $\mathrm{M}$ \\
\hline & $\mathrm{B}_{2}$ & M & $\mathrm{P}$ & $\mathrm{U}$ & $\mathrm{M}$ & $\mathrm{U}$ & $\mathrm{P}$ \\
\hline & $\mathrm{B}_{3}$ & M & $\mathrm{P}$ & M & $\mathrm{P}$ & $\mathrm{MU}$ & SU \\
\hline \multirow[t]{3}{*}{$\mathrm{T}_{4}$} & $\mathrm{~B}_{1}$ & M & $\mathrm{MU}$ & $\mathrm{U}$ & $\mathrm{M}$ & $\mathrm{P}$ & M \\
\hline & $\mathrm{B}_{2}$ & $\mathrm{M}$ & $\mathrm{U}$ & $\mathrm{P}$ & $\mathrm{U}$ & $\mathrm{U}$ & $\mathrm{P}$ \\
\hline & $\mathrm{B}_{3}$ & $\mathrm{P}$ & SU & $\mathrm{MU}$ & $\mathrm{U}$ & $\mathrm{M}$ & MU \\
\hline \multirow[t]{3}{*}{$\mathrm{T}_{5}$} & $\mathrm{~B}_{1}$ & $\mathrm{M}$ & $\mathrm{M}$ & $\mathrm{MU}$ & $\mathrm{M}$ & $\mathrm{P}$ & $\mathrm{M}$ \\
\hline & $\mathrm{B}_{2}$ & MP & $\mathrm{MU}$ & $\mathrm{U}$ & $\mathrm{MU}$ & $\mathrm{P}$ & $\mathrm{P}$ \\
\hline & $\mathrm{B}_{3}$ & $\mathrm{M}$ & SU & $\mathrm{M}$ & SU & $\mathrm{MU}$ & $\mathrm{M}$ \\
\hline \multirow[t]{3}{*}{$\mathrm{T}_{6}$} & $\mathrm{~B}_{1}$ & $\mathrm{P}$ & $\mathrm{P}$ & $\mathrm{M}$ & $\mathrm{MU}$ & SP & SP \\
\hline & $\mathrm{B}_{2}$ & $\mathrm{M}$ & $\mathrm{P}$ & M & $\mathrm{U}$ & $\mathrm{M}$ & $\mathrm{U}$ \\
\hline & $\mathrm{B}_{3}$ & $\mathrm{P}$ & M & SP & $\mathrm{P}$ & $\mathrm{U}$ & $\mathrm{M}$ \\
\hline \multirow[t]{3}{*}{$\mathrm{T}_{7}$} & $\mathrm{~B}_{1}$ & $\mathrm{MU}$ & SP & M & $\mathrm{MU}$ & SU & $\mathrm{P}$ \\
\hline & $\mathrm{B}_{2}$ & $\mathrm{P}$ & M & SP & SU & M & $\mathrm{MU}$ \\
\hline & $\mathrm{B}_{3}$ & SP & SP & $\mathrm{P}$ & $\mathrm{M}$ & $\mathrm{M}$ & SU \\
\hline \multirow[t]{3}{*}{$\mathrm{T}_{8}$} & $\mathrm{~B}_{1}$ & SP & EP & $\mathrm{P}$ & SP & $\mathrm{MU}$ & MP \\
\hline & $\mathrm{B}_{2}$ & M & SP & SP & $\mathrm{P}$ & $\mathrm{P}$ & $\mathrm{P}$ \\
\hline & $\mathrm{B}_{3}$ & SP & $\mathrm{P}$ & $\mathrm{P}$ & $\mathrm{M}$ & SP & $\mathrm{M}$ \\
\hline \multirow[t]{3}{*}{$\mathrm{T}_{9}$} & $\mathrm{~B}_{1}$ & $\mathrm{P}$ & EP & SP & $\mathrm{MU}$ & $\mathrm{P}$ & $\mathrm{P}$ \\
\hline & $\mathrm{B}_{2}$ & SP & $\mathrm{M}$ & M & $\mathrm{U}$ & $\mathrm{MU}$ & $\mathrm{M}$ \\
\hline & $\mathrm{B}_{3}$ & $\mathrm{P}$ & $\mathrm{MU}$ & $\mathrm{U}$ & $\mathrm{M}$ & $\mathrm{M}$ & M \\
\hline \multirow[t]{3}{*}{$\mathrm{T}_{10}$} & $\mathrm{~B}_{1}$ & M & $\mathrm{P}$ & $\mathrm{P}$ & $\mathrm{U}$ & $\mathrm{P}$ & SP \\
\hline & $\mathrm{B}_{2}$ & M & M & MP & $\mathrm{P}$ & M & M \\
\hline & $\mathrm{B}_{3}$ & SP & $\mathrm{P}$ & $\mathrm{M}$ & $\mathrm{P}$ & $\mathrm{U}$ & $\mathrm{U}$ \\
\hline \multirow[t]{3}{*}{$\mathrm{T}_{11}$} & $\mathrm{~B}_{1}$ & M & $\mathrm{M}$ & M & $\mathrm{SP}$ & $\mathrm{MU}$ & $\mathrm{P}$ \\
\hline & $\mathrm{B}_{2}$ & $\mathrm{P}$ & $\mathrm{MU}$ & $\mathrm{P}$ & $\mathrm{MU}$ & $\mathrm{P}$ & M \\
\hline & $\mathrm{B}_{3}$ & SP & $\mathrm{P}$ & $\mathrm{M}$ & $\mathrm{P}$ & $\mathrm{U}$ & SP \\
\hline \multirow[t]{3}{*}{$\mathrm{T}_{12}$} & $\mathrm{~B}_{1}$ & $\mathrm{U}$ & $\mathrm{P}$ & $\mathrm{M}$ & $\mathrm{P}$ & $\mathrm{P}$ & $\mathrm{M}$ \\
\hline & $\mathrm{B}_{2}$ & SP & SP & SP & $\mathrm{M}$ & MP & $\mathrm{U}$ \\
\hline & $\mathrm{B}_{3}$ & $\mathrm{P}$ & $\mathrm{U}$ & $\mathrm{P}$ & $\mathrm{M}$ & $\mathrm{P}$ & $\mathrm{P}$ \\
\hline
\end{tabular}

The summarization of all objectives obtained by the HF-SWARA-MULTIMOORA approach is performed by applying the improved Borda rule, given in Eq. (24) are presented in Table 11.

Finally, the overall ranking of the option is $U_{2}>U_{1}>U_{3}>U_{5}>U_{6}>U_{4}$.; thus, the optimal option is $U_{2}$. 
Table 5 AHF-D matrix for the University over criteria

\begin{tabular}{lllllll}
\hline & $\mathrm{U}_{1}$ & $\mathrm{U}_{2}$ & $\mathrm{U}_{3}$ & $\mathrm{U}_{4}$ & $\mathrm{U}_{5}$ & $\mathrm{U}_{6}$ \\
\hline $\mathrm{T} 1$ & 0.591 & 0.310 & 0.418 & 0.607 & 0.453 & 0.319 \\
$\mathrm{~T} 2$ & 0.579 & 0.299 & 0.571 & 0.516 & 0.551 & 0.481 \\
$\mathrm{~T} 3$ & 0.404 & 0.579 & 0.404 & 0.533 & 0.445 & 0.461 \\
$\mathrm{~T} 4$ & 0.485 & 0.304 & 0.470 & 0.352 & 0.465 & 0.510 \\
$\mathrm{~T} 5$ & 0.498 & 0.384 & 0.384 & 0.376 & 0.560 & 0.550 \\
$\mathrm{~T} 6$ & 0.579 & 0.595 & 0.557 & 0.427 & 0.541 & 0.543 \\
$\mathrm{~T} 7$ & 0.591 & 0.670 & 0.641 & 0.384 & 0.391 & 0.423 \\
$\mathrm{~T} 8$ & 0.680 & 0.783 & 0.677 & 0.644 & 0.618 & 0.518 \\
$\mathrm{~T} 9$ & 0.677 & 0.670 & 0.541 & 0.304 & 0.461 & 0.488 \\
T10 & 0.583 & 0.579 & 0.549 & 0.544 & 0.499 & 0.571 \\
$\mathrm{~T} 11$ & 0.639 & 0.518 & 0.550 & 0.620 & 0.469 & 0.602 \\
$\mathrm{~T} 12$ & 0.610 & 0.587 & 0.641 & 0.517 & 0.607 & 0.493 \\
\hline
\end{tabular}

Table 6 Linguistic values for criteria performances

\begin{tabular}{|c|c|c|c|c|c|c|c|}
\hline \multirow[t]{2}{*}{ Criteria } & \multicolumn{3}{|c|}{ LVs is given by DEs } & \multicolumn{3}{|c|}{ HFNs is given by DEs } & \multirow[t]{2}{*}{$\mathbb{S}\left(\xi_{k j}\right)$} \\
\hline & $\mathrm{B}_{1}$ & $\mathrm{~B}_{2}$ & $\mathrm{~B}_{3}$ & $\mathrm{~B}_{1}$ & $\mathrm{~B}_{2}$ & $\mathrm{~B}_{3}$ & \\
\hline T1 & SU & $\mathrm{P}$ & $\mathrm{P}$ & 0.15 & 0.675 & 0.75 & 0.583 \\
\hline T2 & M & $P$ & $\mathrm{P}$ & 0.50 & 0.675 & 0.75 & 0.593 \\
\hline T3 & $\mathrm{U}$ & M & M & 0.25 & 0.45 & 0.50 & 0.404 \\
\hline T4 & M & M & $\mathrm{P}$ & 0.40 & 0.45 & 0.75 & 0.518 \\
\hline T5 & M & MP & M & 0.45 & 0.55 & 0.60 & 0.533 \\
\hline T6 & $\mathrm{P}$ & $\mathrm{P}$ & $\mathrm{P}$ & 0.6 & 0.675 & 0.675 & 0.647 \\
\hline $\mathrm{T} 7$ & $\mathrm{U}$ & $\mathrm{P}$ & SP & 0.25 & 0.675 & 0.75 & 0.600 \\
\hline T8 & SP & M & SP & 0.75 & 0.45 & 0.75 & 0.670 \\
\hline т9 & $\mathrm{P}$ & MP & $\mathrm{P}$ & 0.60 & 0.55 & 0.675 & 0.607 \\
\hline T10 & $\mathrm{U}$ & $\mathrm{P}$ & MP & 0.30 & 0.675 & 0.55 & 0.528 \\
\hline T11 & MP & $\mathrm{M}$ & SP & 0.55 & 0.50 & 0.75 & 0.610 \\
\hline $\mathrm{T} 12$ & MU & MP & M & 0.40 & 0.55 & 0.50 & 0.483 \\
\hline
\end{tabular}

\subsection{Comparative discussion}

A comparison is discussed to validate the outcomes of the developed HF-SWARAMULTIMOORA framework with the HF-TOPSIS procedure. To assess the above problem, we have taken the HF-TOPSIS approach to compare (Xu and Zhang 2013). The system can be exemplified as.

Step 1-4: Similar to the previous approach.

Step 5: Estimate the Ideal Solution (IS) and Anti-Ideal Solution (AIS).

The IS for numerous criteria are different and described by 
Table 7 Results obtained by SWARA method

\begin{tabular}{llllll}
\hline Criteria & Crisp degrees & $\begin{array}{l}\text { Comparative impor- } \\
\text { tance of criteria }(s j)\end{array}$ & Coefficient $(k j)$ & $\begin{array}{l}\text { Recalculated } \\
\text { weight }(p j)\end{array}$ & Weight $(w j)$ \\
\hline T8 & 0.670 & - & 1.000 & 1.000 & 0.0922 \\
T6 & 0.647 & 0.023 & 1.023 & 0.978 & 0.0902 \\
T11 & 0.610 & 0.037 & 1.037 & 0.943 & 0.0869 \\
T9 & 0.607 & 0.003 & 1.003 & 0.940 & 0.0866 \\
T7 & 0.600 & 0.007 & 1.007 & 0.933 & 0.0860 \\
T2 & 0.593 & 0.007 & 1.007 & 0.927 & 0.0855 \\
T1 & 0.583 & 0.010 & 1.010 & 0.918 & 0.0846 \\
T5 & 0.533 & 0.050 & 1.050 & 0.874 & 0.0806 \\
T10 & 0.528 & 0.005 & 1.005 & 0.870 & 0.0802 \\
T4 & 0.518 & 0.010 & 1.010 & 0.861 & 0.0794 \\
T12 & 0.483 & 0.035 & 1.035 & 0.832 & 0.0767 \\
T3 & 0.404 & 0.079 & 1.079 & 0.771 & 0.0711 \\
\hline
\end{tabular}

Table 8 The preference order of the options-based on the RS procedure

\begin{tabular}{lllllll}
\hline Option & $Y_{i}^{+}$ & $Y_{i}^{-}$ & $y_{i}^{+}$ & $y_{i}^{-}$ & \multicolumn{1}{l}{$y_{i}$} & Ranking \\
\hline $\mathrm{U}_{1}$ & 0.346 & 0.369 & 0.346 & 0.369 & -0.023 & 2 \\
$\mathrm{U}_{2}$ & 0.353 & 0.310 & 0.353 & 0.310 & 0.043 & 1 \\
$\mathrm{U}_{3}$ & 0.308 & 0.344 & 0.308 & 0.344 & -0.036 & 3 \\
$\mathrm{U}_{4}$ & 0.252 & 0.329 & 0.252 & 0.329 & -0.077 & 6 \\
$\mathrm{U}_{5}$ & 0.264 & 0.335 & 0.264 & 0.335 & -0.071 & 5 \\
$\mathrm{U}_{6}$ & 0.272 & 0.316 & 0.272 & 0.316 & -0.044 & 4 \\
\hline
\end{tabular}

$$
\xi^{+}=\left\{\begin{array}{l}
\max _{i=1(1) m} \xi_{i j} \text { for benefit criterion } T_{b} \\
\min _{i=1(1) m} \xi_{i j} \text { for cost criterion } T_{n}
\end{array} \text { for } j=1(1) n\right.
$$

Similarly, the AIS for diverse criteria are defined by

$$
\xi^{-}=\left\{\begin{array}{l}
\min _{i=1(1) m} \xi_{i j} \text { for benefit criterion } T_{b} \\
\max _{i=1(1) m} \xi_{i j} \text { for cost criterion } T_{n}
\end{array} \text { for } j=1(1) n .\right.
$$

Step 6: Calculation of discrimination measures from HF-IS and HF-AIS.

Using Eq. (7), we compute the weighted discrimination measure $D\left(\xi_{i j}, \xi^{+}\right)$with the options $U_{i}(i=1(1) m)$ and the HF-IS $\xi^{+}$and the discrimination measure $D\left(\xi_{i j}, \xi^{-}\right)$with the options $U_{i}(i=1(1) m)$ and the HF-AIS $\xi^{-}$.

Step 7: Estimation of relative closeness coefficient (RCC). 


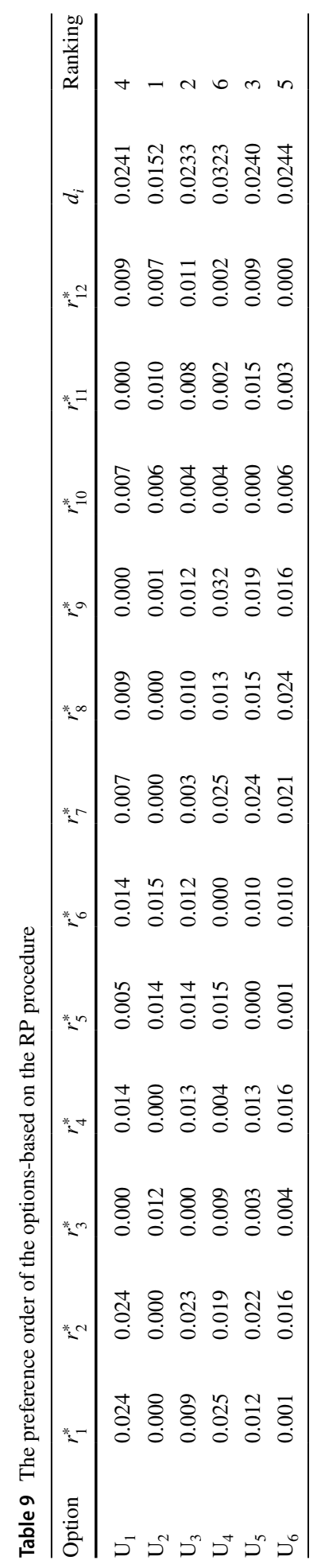


Table 10 The preference order of options-based on the FMF procedure

\begin{tabular}{lllllll}
\hline Option & $A_{i}$ & $B_{i}$ & $\alpha_{i}$ & $\beta_{i}$ & $u_{i}$ & Ranking \\
\hline $\mathrm{U}_{1}$ & 0.811 & 0.709 & 0.811 & 0.709 & 1.143 & 2 \\
$\mathrm{U}_{2}$ & 0.798 & 0.627 & 0.798 & 0.627 & 1.273 & 1 \\
$\mathrm{U}_{3}$ & 0.774 & 0.683 & 0.774 & 0.683 & 1.133 & 4 \\
$\mathrm{U}_{4}$ & 0.707 & 0.668 & 0.707 & 0.668 & 1.058 & 6 \\
$\mathrm{U}_{5}$ & 0.737 & 0.680 & 0.737 & 0.680 & 1.085 & 5 \\
$\mathrm{U}_{6}$ & 0.749 & 0.656 & 0.749 & 0.656 & 1.142 & 3 \\
\hline
\end{tabular}

Table 11 The overall preference order of the options-based on the MULTIMOORA framework

\begin{tabular}{|c|c|c|c|c|c|c|c|c|}
\hline \multirow[t]{2}{*}{ Option } & \multicolumn{2}{|c|}{ RS approach } & \multicolumn{2}{|c|}{$\mathrm{RP}$ approach } & \multicolumn{2}{|c|}{ FMF approach } & \multirow[t]{2}{*}{$I_{B}\left(P_{i}\right)$} & \multirow[t]{2}{*}{ Final Ranking } \\
\hline & $y_{i}^{*}$ & $\rho\left(y_{i}^{*}\right)$ & $d_{i}^{*}$ & $\rho\left(d_{i}^{*}\right)$ & $u_{i}^{*}$ & $\rho\left(u_{i}^{*}\right)$ & & \\
\hline $\mathrm{U}_{1}$ & -0.1795 & 2 & 0.4017 & 4 & 0.4090 & 2 & -0.0459 & 2 \\
\hline $\mathrm{U}_{2}$ & 0.3312 & 1 & 0.2544 & 1 & 0.4555 & 1 & 0.2453 & 1 \\
\hline $\mathrm{U}_{3}$ & -0.2775 & 3 & 0.3897 & 2 & 0.4053 & 4 & -0.0534 & 3 \\
\hline $\mathrm{U}_{4}$ & -0.5961 & 6 & 0.5417 & 6 & 0.3786 & 6 & -0.2167 & 6 \\
\hline $\mathrm{U}_{5}$ & -0.5541 & 5 & 0.4015 & 3 & 0.3881 & 5 & -0.0914 & 4 \\
\hline $\mathrm{U}_{6}$ & -0.3447 & 4 & 0.4092 & 5 & 0.4087 & 3 & -0.1006 & 5 \\
\hline
\end{tabular}

Table 12 Computational outcomes of HF-TOPSIS procedure

\begin{tabular}{lllll}
\hline Option & $D\left(\xi_{i j}, \xi^{+}\right)$ & $D\left(\xi_{i j}, \xi^{-}\right)$ & $C\left(U_{i}\right)$ & Ranking \\
\hline $\mathrm{U}_{1}$ & 0.113 & 0.109 & 0.491 & 2 \\
$\mathrm{U}_{2}$ & 0.067 & 0.156 & 0.700 & 1 \\
$\mathrm{U}_{3}$ & 0.119 & 0.103 & 0.466 & 3 \\
$\mathrm{U}_{4}$ & 0.148 & 0.074 & 0.332 & 6 \\
$\mathrm{U}_{5}$ & 0.141 & 0.081 & 0.365 & 5 \\
$\mathrm{U}_{6}$ & 0.119 & 0.103 & 0.464 & 4 \\
\hline
\end{tabular}

The RCC of each option-based on HF-IS can be computed by utilizing the given formula:

$$
C\left(U_{i}\right)=\frac{D\left(\xi_{i j}, \xi^{-}\right)}{D\left(\xi_{i j}, \xi^{-}\right)+D\left(\xi_{i j}, \xi^{-}\right)}, i=1(1) m .
$$

Step 8: Choose the best University as alternative.

Select the option with maximum RCC degree, represented by $C\left(U_{k}\right)$, among the RCC degrees $C\left(U_{i}\right), i=1(1) m$. and hence $U_{k}$ is the optimal option.

Step 9: End.

From Table 5 and Eqs. (25)-(26), HF-IS and HF-AIS are evaluated. The whole computational results of HF-TOPSIS (Xu and Zhang 2013) are portrayed in Table 12.

Finally, the final ranking of the university is $U_{2}>U_{1}>U_{3}>U_{6}>U_{5}>U_{4}$.; therefore, the most suitable university is $U_{2}$. Observably, the outcomes slightly diverge with various 


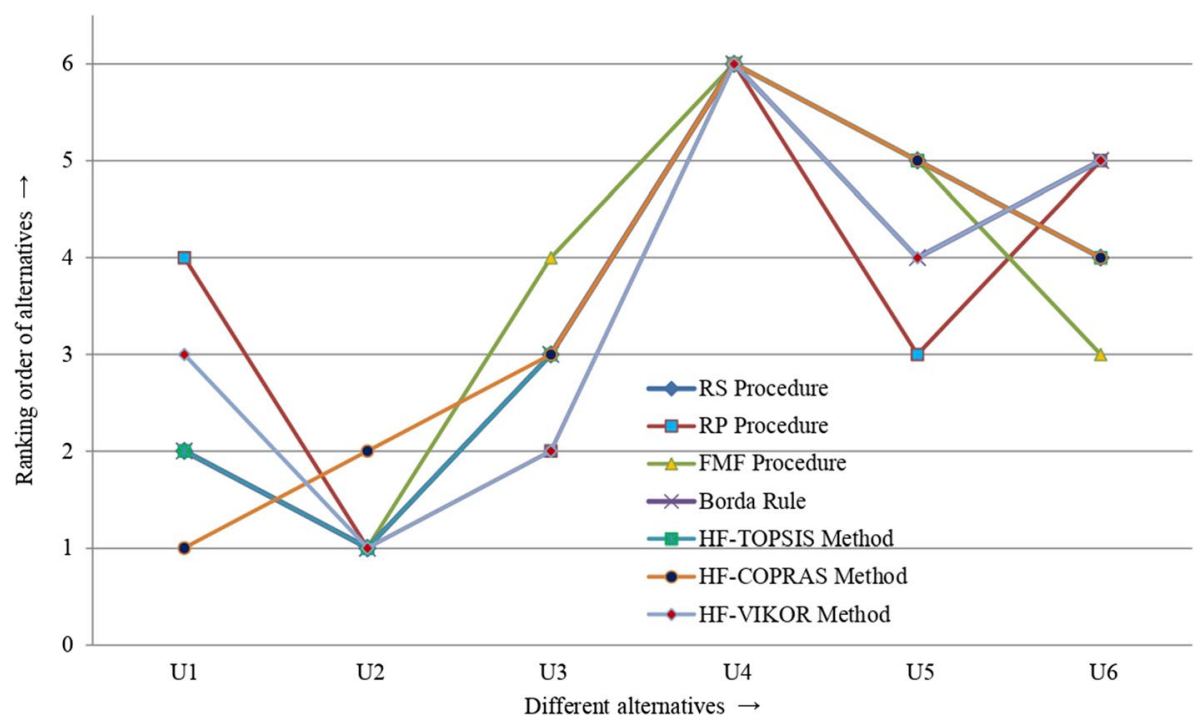

Fig. 1 Comparison of preference order of Universities with various approaches

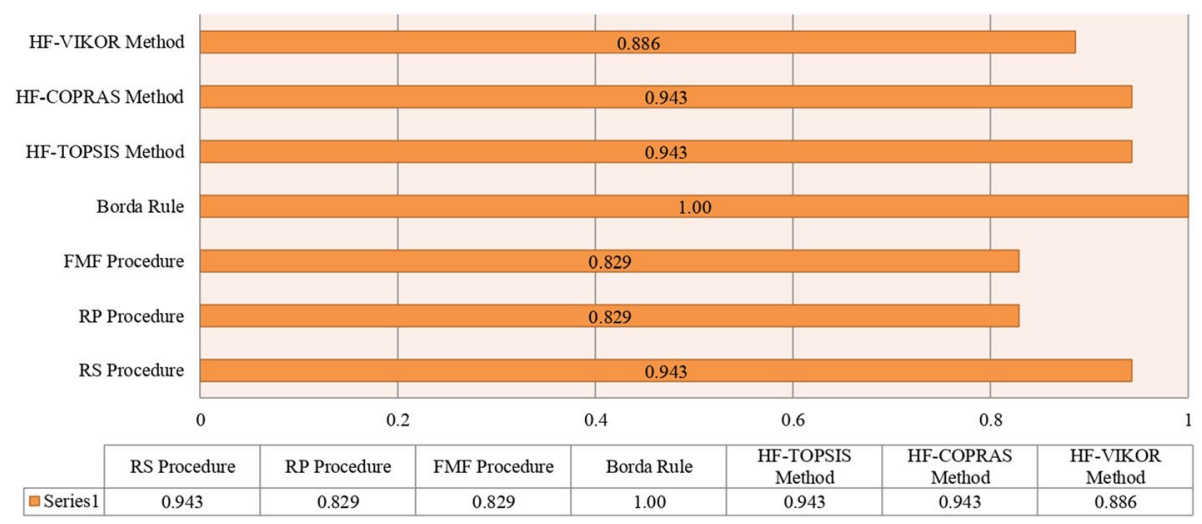

Fig. 2 Correlation plot of various measures of MULTIMOORA approach with the existing approach

types of methods. To this point, the HF-SWARA-MULTIMOORA framework is more robust than the HF-TOPSIS procedure (Xu and Zhang 2013) and thus has a wider range of practicality.

Also, we have compared the proposed HF-SWARA-MULTIMOORA framework with other extant methods namely, HF-VIKOR (Liao and Xu 2019) method and HF-COPRAS (Mishra et al. 2019a) method. Figure 1 depicts the prioritization order from different methods with HFSs and discusses different factors to recognize the developed framework's strengths. From Fig. 2, it is obtained that the developed approach is highly consistent with the existing method with HFSs. To retain homogeneity in the method-related comparison, we consider the method viz., HF-TOPSIS (Xu and Zhang 2013), HF-VIKOR (Liao and Xu 2013) and HF-COPRAS (Mishra et al. 2019a). From Fig. 2, it is clear that the consistency of the developed framework is high with existing methods. The Spearman correlation 
values of RS procedure, RP procedure, FMF procedure, Borda Rule, HF-TOPSIS, HFCOPRAS and HF-VIKOR with the final ranking solution $(0.943,0.829,0.829,1.000 .943$, $0.943,0.886)$. Spearman correlation is utilized to these rank values to determine the consistency of the developed framework.

The main benefits of the proposed HF-SWARA-MULTIMOORA are as follows:

- The HFS can reflect the DE's hesitancy more objectively than other classical extensions of FSs. Therefore, the use of developed HF-SWARA-MULTIMOORA approach gives a more flexible way to express the uncertainty in adapting online education for the control of the pandemic spread of COVID-19 in higher education institutions.

- In the developed method, the SWARA technique is utilized for the assessment of criteria weights, which makes the proposed HF-SWARA-MULTIMOORA approach more efficient, sensible and reliable tool.

- The proposed HF-SWARA-MULTIMOORA approach is not only suitable for evaluating the MCDM problems under HFSs context, but can also successfully tackle with the MCDM problems under fuzzy sets, intuitionistic fuzzy sets and type-2 fuzzy sets contexts. The developed method has the benefits of accurate and reliable results, and fast information processing.

- Obviously, the results slightly vary with different types of weights for the criteria. To this point, the HF-SWARA-MULTIMOORA method is more robust than the HFTOPSIS method and thus has wider applicability. Furthermore, both the HF-VIKOR method and the HF-TOPSIS method fail to tackle the case that the weight vector of the criteria is completely unknown.

- For the HF-TOPSIS and HF-VIKOR model, it is necessary to calculate the discriminations between each alternative on each criterion and that of the HF-IS, which is timeconsuming and reduces the accuracy of the results. Also, the HF-COPRAS method is utilized HFWAO and score function to calculate the utility degree, while in proposed method, we utilize HFWAO, HFWGO, HF-IS and score function to evaluate the preference order of alternatives. In this reason, the proposed HF-SWARA-MULTIMOORA method is superior to the HF-VIKOR method, HF-COPRAS method and the HF-TOPSIS method.

Some limitations of the proposed method are as follows:

- In the proposed HF-SWARA-MULTIMOORA method, all criteria are assumed to be independent. In reality, there are interrelationships among the criteria.

- This method has limitation in order to deal with a large number of criteria.

\section{Conclusion and discussions}

The present study investigated the key challenges to adapt online education in higher institutions in Iran universities using an integrated decision-making framework. A survey using interviews and literature review has been used to find and evaluate the critical challenges for controlling the pandemic spread of novel coronavirus (COVID-19) in higher education. A learning theory is used to develop a comprehensive framework based on three main challenges: systemic challenges, pedagogical challenges, and psychological challenges. Besides, to evaluate these key challenges, several criteria lack of technical support, lack of 
online technologies, cost constraints, lack of policies, quality of materials, lack of experience, online assessment, student engagement, lack of practical classes lockdown pressure, time pressure and fear of digitalization are identified using experts opinions and literature review. This study presents a novel integrated framework based on the SWARA approach and the MULTIMOORA approach on HFSs. In the proposed framework, the SWARA approach has been applied to elicit the preferences of a set of DEs under uncertainty, and then, an aggregated subjective weight has been provided for each challenge to adapt the online education during the COVID-19 outbreak. Next, the MULTIMOORA approach has been applied to evaluate the ranking order of higher education institutions. The comparative study has been discussed to validate the results, verifying the reasonability of the HFSWARA-MULTIMOORA framework. According to the study results, the first rank was related to pedagogical challenges, including a lack of experience and student engagement.

It is noticeable that educational leaders should develop professional opportunities to boost online education quality and efficacy, while the number of students interested in online education has increased dramatically (Ganza 2012). Besides, institutions and governments should propose and employ proper methods and tools to assess proposed professional opportunities' effectiveness and performance. The results indicated a mixture of challenges having considerable effects on the process of adapting online education during the COVID-19 pandemic. Besides, each of the identified challenges has either a negative or positive effect on the adaption process, especially on the design delivery, while the design delivery has a crucial role in evaluating the adaption process. Furthermore, higher education institutions have a crucial role in boosting the quality of online education through supporting students, teachers, and content development, while it is believed that online education will be an inseparable part of higher education in the future (Wickersham and McElhany 2010). On top of that, many scholars and the present research concluded that institutions should deal with variant challenges to boost the quality of online education effectively (Kebritchi et al. 2017; Lion and Stark 2010; Prestera and Moller 2001); however, how institutions should deal with identified challenges, or what are the new platforms for online education, or what are the new learning theories being applicable during challenging situations such as COVID-19 pandemic can be considered as research avenues for future research.

\section{References}

Anderson T (2008) Towards a theory of online learning. Theory Pract Online Learn 2:109-119

Arbaugh JB (2005) Is there an optimal design for on-line MBA courses? Acad Manag Learn Educ 4(2):135-149

Atanassov K (1986) Intuitionistic fuzzy sets. Fuzzy Sets Syst 20(1):87-96

Babu J, Jayakumar P (2020) Academic engagement of college students during the national lockdown due to Covid-19. GIS-Bus 15:463-482

Bao W (2020) "Covid-19 and online teaching in higher education: a case study of Peking University. Hum Behav Emerg Technol. https://doi.org/10.1002/hbe2.191

Bates AT, and San Francisco JBI (2001) Managing Technological Change-Strategies for Colleges and University Leaders, New technology in the human services), p. 55

Bennett S, Lockyer L (2004) Becoming an online teacher: adapting to a changed environment for teaching and learning in higher education. Educ Media Int 41(3):231-248

Bizaer M (2020) Pandemic reveals iran's online-learning challenges. Retrieved 17 April 2020, 2020, from https://www.al-monitor.com/pulse/originals/2020/04/iran-pandemic-online-learning-challenges-coron avirus-covid19.html

Brauers WK, Zavadskas EK (2006) the moora method and its application to privatization in a transition economy. Control Cybern 35:445-469 
Brauers WKM, Zavadskas EK (2010) Project Management by Multimoora as an Instrument for Transition Economies. Technol Econ Dev Econ 16(1):5-24

Brauers WKM, Zavadskas EK (2012) Robustness of multimoora: a method for multi-objective optimization. Informatica 23(1):1-25

Cecilio-Fernandes D, Parisi MCR, Santos TM, Sandars J (2020) The Covid-19 pandemic and the challenge of using technology for medical education in low and middle income countries. MedEdPublish. https://doi.org/10.15694/mep.2020.000074.1

Crawford J, Butler-Henderson K, Rudolph J, Glowatz M (2020) Covid-19:20 Countries' higher education intra-period digital pedagogy responses. J Appl Teach Learn JALT. https://doi.org/10.37074/ jalt.2020.3.1.7

Damary R, Markova T, Pryadilina N (2017) Key Challenges of on-line education in multi-cultural context. Procedia Soc Behav Sci 237:83-89

Dwidienawati D, Musrin M (2020) Forced shifting to e-learing during Covid-19 outbreak-information quality system quality service quality and goal orientation influence to satisfaction and performance. Int J Adv TrendsComput Sci Eng. https://doi.org/10.30534/ijatcse/2020/93922020

Esfijani A (2018) Measuring quality in online education: a meta-synthesis. Am J Distance Educ 32(1):57-73

Evans T, Haughey M, Murphy D (2008) International handbook of distance education. Emerald Group Publishing

Ganza W (2012) The Impact of Online Professional Development on Online Teaching in Higher Education

Gewin V (2020) Five tips for moving teaching online as Covid-19 takes hold. Nature 580(7802):295-296

Gillett-Swan J (2017) The challenges of online learning: supporting and engaging the isolated learner. J Learn Des 10(1):20-30

Gössling S, Scott D, Hall CM (2020) Pandemics, tourism and global change: a rapid assessment of Covid-19. JSustain Tour 29:1-20

Grammegna A (2020) The new challenge of education value and limits of distance learning today. J Educ Cult Stud 4(2):59

Howell SL, Saba F, Lindsay NK, Williams PB (2004) Seven strategies for enabling faculty success in distance education. Internet Higher Educ 7(1):33-49

Huang Y (2020) "Research on online education in the midst of the Covid-19 pandemic. J Adv Educ Res. https://doi.org/10.22606/jaer.2020.52005

Jacobs P (2014) Engaging students in online courses. Res Higher Educ J 26: 1-9

Jadhav V (2020) Health Education: During Lockdown

Jaggars SS (2014) Choosing between online and face-to-face courses: community college student voices. Am J Distance Educ 28(1):27-38

Kazmi SSH, Hasan K, Talib S, and Saxena S (2020) Covid-19 and lockdwon: a study on the impact on mental health, Available at SSRN 3577515

Kebritchi M, Lipschuetz A, Santiague L (2017) Issues and challenges for teaching successful online courses in higher education: a literature review. J Educ Technol Syst 46(1):4-29

Keršuliene V, Zavadskas EK, Turskis Z (2010) Selection of rational dispute resolution method by applying new step-wise weight assessment ratio analysis (Swara). J Bus Econ Manag 11(2):243-258

Koole M (2014) Identity and the itinerant online learner. Int Rev Res Open Distrib Learn 15(6):52-70

Lau H, Khosrawipour V, Kocbach P, Mikolajczyk A, Schubert J, Bania J, Khosrawipour T (2020) The positive impact of lockdown in wuhan on containing the Covid-19 outbreak in China. J Travel Med. https://doi.org/10.1093/jtm/taaa037

Li CS, and Irby B (2008) an overview of online education: attractiveness, benefits, challenges, concerns and recommendations, College Student Journal 42, 2

Li C, Zhao H, and Xu Z (2020) Hesitant fuzzy psychological distance measure, Int J Mach Learn Cybern, pp. 1-12

Liao H, Xu Z (2013) A VIKOR-based method for hesitant fuzzy multi-criteria decision making. Fuzzy Optim Decis Making 12(04):373-392

Liao H, Xu Z, Xia M (2014) Multiplicative consistency of hesitant fuzzy preference relation and its application in group decision making. Int J Inf Technol Decis Mak 13(01):47-76

Liao Z, Liao H, Gou X, Xu Z, Zavadskas EK (2019) A hesitant fuzzy linguistic choquet integral-based multimoora method for multiple criteria decision making and its application in talent selection. EconComput Econ Cybern Stud Res 53(2):113

Lion RW, Stark G (2010) A glance at institutional support for faculty teaching in an online learning environment. Educ Q 33(3):23-39

Liu X, Bonk CJ, Magjuka RJ, Lee S-H, Su B (2005) Exploring four dimensions of online instructor roles: a program level case study. J Asynchronous Learn Netw 9(4):29-48 
Lloyd SA., Byrne MM. and McCoy TS (2012) Faculty-perceived barriers of online education, J Online Learn Teach 8, 1

Longhurst GJ, Stone DM, Dulohery K, Scully D, Campbell T, Smith CF (2020) Strength, weakness, opportunity, threat (swot) analysis of the adaptations to anatomical education in the united kingdom and republic of ireland in response to the Coivd-19 pandemic. Anat Sci Educ. https://doi.org/10.1002/ase. 1967

Mardani A, Saraji MK, Mishra AR, Rani P (2020) A novel extended approach under hesitant fuzzy sets to design a framework for assessing the key challenges of digital health interventions adoption during the Covid-19 outbreak. Appl Soft Comput 96:106613

McInnerney JM, Roberts TS (2004) Online learning: social interaction and the creation of a sense of community. J Educ Technol Soc 7(3):73-81

Mishra AR, Rani P, Pardasani KR (2019a) Multiple-criteria decision-making for service quality selection based on shapley copras method under hesitant fuzzy sets. Granul Comput 4(3):435-449

Mishra AR, Rani P, Pardasani KR, Mardani A (2019) A novel hesitant fuzzy waspas method for assessment of green supplier problem based on exponential information measures. J Clean Prod 238:117901

Mishra AR, Rani P, Pandey K, Mardani A, Streimikis J, Streimikiene D, Alrasheedi M (2020) Novel multicriteria intuitionistic fuzzy swara-copras approach for sustainability evaluation of the bioenergy production process. Sustainability 12(10):4155

Mustafa N (2020) Impact of the 2019-20 coronavirus pandemic on education. Int J Health Prefer Res $5(20): 13$

Naciri A, Kharbach A (2020) Mobile learning in higher education: unavoidable alternative during Covid-19. Aquademia 4:20016

Prestera GE, and Moller LA (2001) Organizational alignment supporting distance education in post-secondary institutions. Annual Proceedings of Selected Research and Development [and] Practice Papers Presented at the National Convention of the Association for Educational Communications and Technology (24th, Atlanta, GA, November 8-12, 2001). Volumes 1-2; see IR 021504.

Rani P, Mishra AR, Mardani A, Cavallaro F, Štreimikienė D, Khan SAR (2020) Pythagorean fuzzy swaravikor framework for performance evaluation of solar panel selection. Sustainability 12(10):4278

Romero-Rodríguez J, Aznar-Díaz I, F, Gómez-García G (2020) Mobile learning in higher education: structural equation model for good teaching practices. Ieee Access 8:91761-91769.

Rovai AP, Barnum KT (2007) On-line course effectiveness: an analysis of student interactions and perceptions of learning. Int J E-Learn Distance Educ/Revue Int Du e-Learn Et La Formation à Distance 18(1):57-73

Rumble G (2004) Papers and debates on the economics and costs of distance and online learning. bibliotheks-und informationssystem der Universität Oldenburg Oldenburg

Shamsy J (2014) A balancing act part i: technical support and the online instructor. eLearn 5:4

Spiceland CP, Spiceland JD, Schaeffer S III (2015) Using a course redesign to address retention and performance issues in introductory accounting. J Account Educ 33(1):50-68

Strielkowski W (2020) Covid-19 pandemic and the digital revolution in academia and higher education

Torra V (2010) Hesitant fuzzy sets. Int J Intell Syst 25(6):529-539

Torra V, and Narukawa Y (2009) On hesitant fuzzy sets and decision, 2009 IEEE International Conference on Fuzzy Systems: IEEE, pp. 1378-1382

Trow M (2007) Reflections on the transition from elite to mass to universal access: forms and phases of higher education in modern societies since Wwii, In: international handbook of higher education. Springer, pp. 243-280

Vlachopoulos D (2020) Covid-19: threat or opportunity for online education? Higher Learn Res Commun 10(1):2

Waterhouse S, Rogers RO (2004) The importance of policies in e-learning instruction. Educ Q 27(3):28-39

Wickersham LE, McElhany JA (2010) Bridging the divide: reconciling administrator and faculty concerns regarding online education. Q Rev Distance Educ 11(1):1

Wu X, Liao H, Xu Z, Hafezalkotob A, Herrera F (2018) Probabilistic linguistic multimoora: a multicriteria decision making method based on the probabilistic linguistic expectation function and the improved borda rule. IEEE Trans Fuzzy Syst 26(6):3688-3702

Xia M, Xu Z (2011) Hesitant fuzzy information aggregation in decision making. Int J Approx Reason 52(3):395-407

Xu Z, Zhang X (2013) Hesitant fuzzy multi-attribute decision making based on topsis with incomplete weight information. Knowl-Based Syst 52:53-64

Yager RR (1986) On the theory of bags. Int J Gen Syst 13(1):23-37

Zadeh LA (1975) The concept of a linguistic variable and its application to approximate reasoning-Iii. Inf Sci 9(1):43-80 
Zapalska A, Brozik D (2006) Learning styles and online education. Campus-Wide Inform Syst 23:325-335 Zayapragassarazan Z (2020) "Covid-19: strategies for engaging remote learners in medical education. Education 1000(9):273

Zhang C, Chen C, Streimikiene D, Balezentis T (2019) Intuitionistic fuzzy multimoora approach for multicriteria assessment of the energy storage technologies. Appl Soft Comput 79:410-423

Zhao H, Xu Z, Wang H, Liu S (2017) Hesitant fuzzy multi-attribute decision-making based on the minimum deviation method. Soft Comput 21(12):3439-3459

Publisher's Note Springer Nature remains neutral with regard to jurisdictional claims in published maps and institutional affiliations.

\section{Authors and Affiliations}

\section{Mahyar Kamali Saraji ${ }^{1,6} \cdot$ Abbas Mardani $^{2}$ - Mario Köppen ${ }^{3} \cdot$ Arunodaya Raj Mishra $^{4}$. Pratibha Rani ${ }^{5}$}

Mahyar Kamali Saraji

Mahyar.Kamali@knf.stud.vu.lt

1 Faculty of Economics, Management, and Accounting, Yazd University, Yazd, Iran

2 University of South Florida, Tampa, FL, United States

3 Kyushu Institute of Technology, Department of Artificial Intelligence, 680-4 Kawazu, Lizuka, Fukuoka 820-8502, Japan

4 Department of Mathematics, Govt. College Jaitwara, Satna, MP, India

5 Department of Mathematics, National Institute of Technology, Warangal 506004, India

6 Kaunas Faculty, Vilnius University, Muitines 8, LT-44280 Kaunas, Lithuania 